\title{
Evaluación de parámetros productivos y nutricionales por el uso de Lactobacilius acidophilus y Lactobacilius bifidus en la dieta del hámster dorado (Mesocricetus auratus)
}

\author{
José R. Corredor-Matus*, MVZ, Dip. MsC ${ }_{1}$, Cristina Hernández, MVZ, Esp, MsC(c) ${ }_{1}$, Andrés Arias, MVZ
}

${ }_{1}$ Universidad de los Llanos, Grupo de estudio prebióticos.

Recibido: 18 de octubre del 2014. Aprobado: 15 de diciembre de 2014.

*Autor de correspondencia: José R. Corredor-Matus. Escuela de Ciencias Animales, Universidad de los Llanos. Km. 12 vía Puerto López, Villavicencio, Colombia. Teléfono: (57)8+6616800 ext 145. Correo electrónico: jcorredormatus@gmail.com

Cómo citar este artículo: Corredor-Matus JR, Hernández C, Arias A. Evaluación de parámetros productivos y nutricionales por el uso de Lactobacilius acidophilus y Lactobacilius bifidus en la dieta del hámster dorado (Mesocricetus auratus). Spei Domus. 2014;10(20):41-48. doi: http://dx.doi.org/10.16925/sp.v10i21.917

Resumen. Introducción: los probióticos han sido considerados por muchos autores como microorganismos que afectan benéficamente la flora intestinal, de tal manera que sus efectos no sólo se han reportado en tracto gastrointestinal, también en el respiratorio y urogenital. El objetivo del presente trabajo fue evaluar parámetros productivos (crecimiento y ganancia de peso) y nutricionales (contenido fecal de nitrógeno, grasa, cenizas y humedad) por el suministro de un coctel probiótico (que contenía Lactobacilius acidophilus y Lactobacilius bifidus), de uso comercial en el hámster dorado. Materiales y métodos: para ello, se escogieron 20 animales experimentales con una edad promedio de 8 a 15 días, los cuales se dividieron en dos grupos experimentales: control (GCJ) y experimental (GMS), por un periodo de 3 semanas. Se midieron variables de peso (gramos) y longitud (centímetros) semanalmente, así como análisis proximal de heces para determinar contenido de nitrógeno, grasa, cenizas y humedad. Los datos se expresan en promedios \pm ds, para las variables de Crecimiento y Ganancia de peso. Resultados: el suministro de probióticos afectó significativamente la ganancia de peso y el crecimiento, generó disminución en la excreción fecal de nitrógeno, interpretado como mayor digestión y absorción de proteínas, una reducción en la eliminación de cenizas y mayor excreción fecal de grasas, atribuida principalmente al exceso de este nutriente en la dieta suministrada. Conclusiones: el uso de probióticos es una herramienta muy útil para ser usada en los sistemas productivos, en reemplazo de otros productos que pueden generar riesgos a la salud pública.

Palabras clave: crecimiento, ganancia de peso, nitrógeno fecal, nutrición, probióticos.

Evaluation of Productive and Nutritional Parameters for the Use of Lactobacillus acidophilus and Lactobacillus bifidus in the Diet of the Golden Hamster (Mesocricetus auratus)

\footnotetext{
Abstract. Introduction: many authors have regarded probiotics as microorganisms that are beneficial for gut flora, working through various mechanisms and with effects reported not only in the gastro-intestinal tract but also in the respiratory and urogenital tracts. The aim of this study was to evaluate productive parameters (growth and weigh gain) and nutritional parameters (fecal content of nitrogen, fat, ash and moisture) against the supply of a commercially used probiotic cocktail containing Lactobacillus acidophilus and Lactobacillus bifidus in the golden hamster. Materials and methods: we selected 20 experimental animals with an average age between 8 and 15 days. These were then divided into two experimental groups: control (GCJ) and experimental (GMS). Each week for 3 weeks we measured weight (grams) and length (centimeters) variables, and conducted a proximate analysis of feces to determine the nitrogen, fat, ash and moisture content. Data were expressed in \pm SD averages for the variables of growth and weight gain. Results: the results obtained showed that administering the probiotic significantly affected weight gain and growth, reduced fecal excretion of nitrogen (interpreted
}

as better digestion and absorption of proteins), reduced ash elimination, and increased fecal excretion of fat, which was largely attributed to an excess of this nutrient in the diet provided. Conclusions: the use of probiotics is an extremely useful tool that can be used in production systems to replace other products that may generate public health risks.

Keywords: growth, weight gain, fecal nitrogen, nutrition, probiotics.

\section{Avaliação de parâmetros produtivos e nutricionais pelo uso de Lactobacilius acidophilus $e$ Lactobacilius bifidus na dieta do hamster dourado (Mesocricetus auratus)}

Resumo. Introdução: os probióticos foram considerados por muitos autores como micro-organismos que afetam beneficamente a flora intestinal, por distintos mecanismos, de tal maneira que seus efeitos não só se reportaram em trato gastrointestinal, como também no respiratório e urogenital. O objetivo do presente trabalho foi avaliar parâmetros produtivos (crescimento e ganho de peso) e nutricionais (conteúdo fecal de nitrogênio, gordura, cinzas e umidade) fornecendo um coquetel probiótico que continha Lactobacilius acidophilus e Lactobacilius bifidus, 
de uso comercial no hamster dourado. Materiais e métodos: foram escolhidos 20 animais experimentais com uma média de idade de 8 a 15 dias, que se dividiram em dois grupos experimentais: controle (GCJ) e experimental (GMS), por um periodo de 3 semanas. Mediram-se variáveis de peso (gramas) e longitude (centímetros) semanalmente, assim como análise proximal de fezes para determinar conteúdos de nitrogênio, gordura, cinzas e umidade. Os dados expressam em média \pm ds, para as variáveis crescimento e ganho de peso. Resultados: os resultados obtidos mostraram que o fornecimento de probiótico afetou significativamente

\section{Introducción}

En los sistemas productivos, la cría intensiva animal ha aumentado considerablemente, hecho que tiende a acrecentar problemas en la salud de las explotaciones, afectando su fisiología y, como consecuencia, causando efectos nocivos en la economía. Durante toda la historia, se ha investigado en busca de aditivos que mejoren el bienestar animal y el comportamiento productivo, estableciéndose por primera vez en 1965 el término de probiótico [1-3].

En décadas pasadas, el método más común para prevenir enfermedades y aumentar la eficiencia alimentaria fue el uso de antibióticos como aditivo alimentario, pero se ha comprobado que tienen influencias negativas en la eubiosis del sistema gastrointestinal, además de que dan lugar a la aparición de la resistencia bacteriana a estos fármacos y a su presencia residual en las carnes, huevos, leche y otros productos de origen animal. Es por ello que se han introducido los probióticos como una solución alternativa promisoria $[2,4]$.

Los problemas entéricos, especialmente en lechones y en muchos otros mamíferos de interés zootécnico, son una de las principales causas de pérdidas económicas en la industria. La totalidad de las granjas porcinas utiliza antibióticos de manera terapéutica y subterapéutica para controlar estos problemas; no obstante, su uso prolongado puede generar resistencia en cierto tipo de bacterias patógenas, pero se debe insistir en la búsqueda de otras alternativas que ofrezcan mejores o similares beneficios que los antibióticos y que, a su vez, no sean perjudiciales para los animales ni para el hombre $[5,6]$.

Los probióticos han sido señalados como posibles reemplazos de los antibióticos. Estos han sido definidos como microorganismos vivos que ejercen un efecto benéfico para el tracto intestinal del hospedero, manteniendo y reforzando los mecanismos de defensa ante patógenos, sin perturbar las funciones fisiológicas y bioquímicas normales, cuando modulan la microflora intestinal [6-10]. o ganho de peso e crescimento, gerou diminuição na excreção fecal de nitrogênio, interpretado como maior digestão e absorção de proteínas, uma redução na eliminação de cinzas e maior excreção fecal de gorduras, atribuída principalmente ao excesso deste nutriente na dieta fornecida. Conclusões: o uso de probióticos é uma ferramenta muito útil para ser usada nos sistemas produtivos, no lugar de outros produtos que podem gerar riscos à saúde pública.

Palavras-chave: crescimento, ganho de peso, nitrogênio fecal, nutrição, probióticos.
Debido a los beneficios que potencialmente se pueden derivar como resultado de la manipulación de la flora intestinal en términos de prevención de infección gastrointestinal, cáncer y enfermedad cardiovascular, supresión de bacterias nocivas y promoción del desarrollo de bacterias benéficas, recientemente se ha generado un gran interés en el desarrollo de productos que permitan la posibilidad de modificar la flora intestinal por medios dietéticos. El valor de los probióticos y los prebióticos radica en su uso como agentes profilácticos, y su incorporación en alimentos es el mecanismo más adecuado para asegurar la presencia de bacterias benéficas en el intestino [11], con beneficios nutricionales y terapéuticos $[8,12-15]$. Entre los prebióticos más utilizados con fines terapéuticos se encuentran, principalmente, los del género Lactobacillus y Bifidobacterium $[5,12,14]$.

De acuerdo con lo anterior, el objetivo de este proyecto fue evaluar el efecto nutricional del uso de los probióticos L. acidophilus y L. bifidus, a través de la valoración del crecimiento y ganancia de peso, así como por la determinación de nitrógeno, grasa, cenizas y humedad fecal en hámster dorado, sometidos a una dieta que contenía estos probióticos.

\section{Materiales y métodos}

El proyecto se realizó en la Universidad de los Llanos, ubicada en Villavicencio, Meta, Colombia, a una temperatura ambiente que oscila entre 24-34 grados centígrados, una altitud de $410 \mathrm{msnm}$, una precipitación pluvial media de $3500 \mathrm{~mm}$ año y humedad relativa promedio del $85 \%$. No se consideraron las condiciones ambientales dentro de la instalación en que se mantuvieron los ejemplares experimentales.

Se utilizaron 20 animales hámster dorado (Mesocricetus auratus) clínicamente sanos, destetos, los cuales fueron divididos al azar en dos grupos y se colocaron 
en jaulas separadas, ubicadas en las instalaciones de la Granja Barcelona de Unillanos. Se establecieron dos grupos: uno experimental (GMS) con diez ejemplares y otro control (GCJ) con igual número de animales. Los ejemplares fueron alimentados ad libitum con alimento comercial para caninos lactantes y a libre disponibilidad de agua. Las jaulas permanecieron unidas para evitar que factores como: temperatura, humedad, iluminación, estrés, rayos UV, entre otros, incidieran en los resultados.

Al grupo GMs se le suministró mezclado en el alimento el probiótico L. acidophilus y L. bifidus, durante 3 semanas, con el fin de esperar una mayor absorción de nutrientes. El probiótico se aplicó disolviéndolo en solución salina $2 \mathrm{~g}$ del agente por kilo de concentrado, para asegurar una concentración de $10^{7} \mathrm{ufc} / \mathrm{g}$ de dieta experimental, que se mantuvo constante a lo largo del estudio. Todos los animales (2 grupos) del estudio se sometieron a un periodo de adaptación de diez días, a las condiciones de reclusión y dieta, antes de iniciar el protocolo experimental. Los animales GCJ se alimentaron al mismo tiempo que los del grupo GMs.

Los animales de los dos grupos fueron muy uniformes y pesados al inicio del tratamiento; luego, se realizaron pesajes semanales por tres semanas, con el fin de determinar la ganancia de peso. El pesaje se realizó en una balanza de precisión digital en forma individual y el resultado se reportó en valor promedio del peso en gramos y desviación estándar $(\mathrm{DE})$.

La talla se determinó por la distancia obtenida desde el inicio de la nariz, hasta el final de la cola, medida hecha al comenzar el tratamiento, y luego cada semana, durante tres semanas. El resultado se reporta en promedio en centímetros y DE.

Se realizó un análisis proximal al alimento suministrado con el fin de establecer su calidad nutricional respecto al nivel de proteína, grasa, cenizas y humedad. Posteriormente, se tomaron muestras de excretas a los dos grupos para determinar el grado de absorción de nutrientes, mediante su análisis proximal al final de la primera, segunda y tercera semana de iniciado el tratamiento. Estos procedimientos se realizaron en las instalaciones del laboratorio de nutrición animal de Unillanos, cumpliendo con los protocolos establecidos por el laboratorio para este tipo de análisis. Las variables que se analizaron en las heces incluyeron el nitrógeno fecal, grasa, ceniza y humedad.

Los datos se reportan en promedios y DE. Se realizó una prueba $\mathrm{T}$ de Student para determinar diferencias estadísticas entre grupos, para las variables crecimiento y ganancia de peso, para lo cual se estableció un nivel de significancia de alfa de 0,05.

\section{Resultados}

Se sometió una muestra de ejemplares hámster dorado a la suplementación con probióticos del género Lactobacillus, para verificar su acción en parámetros productivos. La figura 1 muestra el análisis nutricional realizado al alimento suministrado. Se observa un alto contenido de grasa, cerca del $35 \%$.

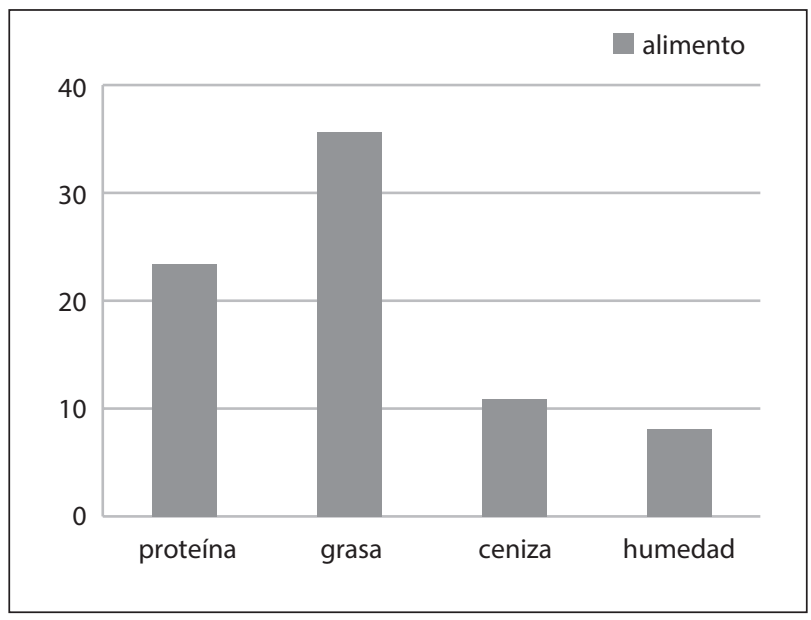

Figura 1. Análisis proximal del alimento suministrado a los dos grupos experimentales.

Fuente: elaboración propia

Los sujetos experimentales no presentaron ningún tipo de dificultad para consumir el alimento. El diseño del experimento incluía una medición de la ganancia de peso semanal a los dos grupos. La figura 2 muestra el comportamiento de este parámetro, partiendo del peso inicial que registró un promedio para el grupo control de 35,12 $\pm 6,54$ gramos, mientras que, para el experimental, fue de 35,8 \pm 6,6 gramos, sin que, por supuesto, se registraran diferencias significativas entre los dos grupos $(p=0,4117)$. A la primera semana, el grupo control alcanzó un peso de 65,78 \pm 6,03 gramos, mientras que el experimental registró 68,94 \pm 6,26 gramos, sin diferencias significativas a esta edad ( $p=$ $0,1463)$. Para la segunda semana, el peso promedio del grupo control fue de $86,54 \pm 3,17$ gramos, en tanto que el del grupo experimental fue de $94,87 \pm 7,9$ gramos, una diferencia altamente significativa entre ellos $(p=$ $0,0045)$. Los registros de la tercera y última semana del experimento arrojaron valores de 91,12 \pm 4,41 gramos y $102,31 \pm 4,6$ para el control y experimental, 
respectivamente, con lo que se estableció una diferencia altamente significativa entre ellos $(p=0,00021)$, lo que demuestra, en definitiva, que el uso de los probióticos influenció directamente la ganancia de peso de los ejemplares que lo recibieron.

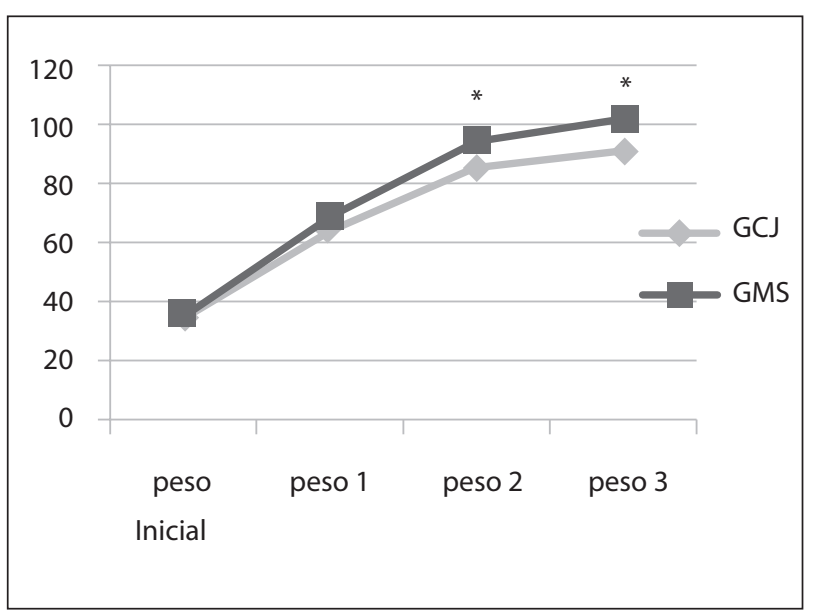

${ }^{*}$ Indica diferencias significativas

Figura 2. Registro de ganancia de peso (gramos) en hámster dorado control y suplementados con probióticos Fuente: elaboracion propia

Respecto a la talla, la figura 3 muestra el comportamiento de los dos grupos, teniendo en cuenta que los registros iniciales para ellos fueron de 11,28 $\pm 0,83 \mathrm{~cm}$ para el control y $11,38 \pm 0,65 \mathrm{~cm}$ para el experimental. Las mediciones de la primera semana alcanzaron los $13,1 \pm 0,62$ y $14,3 \pm 0,54 \mathrm{~cm}$ para control y experimental en su orden, mostrando diferencias altamente significativas entre los dos grupos $(p=0,00024)$. En la segunda semana la talla alcanzó los 13,9 $\pm 0,42$ y $15,2 \pm 0,77 \mathrm{~cm}$ para control y experimental, con diferencias altamente significativas $(p=0,00019)$. La última medida de talla a la tercera semana fue de $14,18 \pm 0,35 \mathrm{~cm}$ y $15,5 \pm 0,35 \mathrm{~cm}$ para el control y experimental, respectivamente, con diferencias altamente significativas ( $p=0,000098)$. De forma similar a lo registrado con el peso, es claro que el uso de los probióticos influyó positivamente en la mejor talla alcanzada por los ejemplares experimentales.

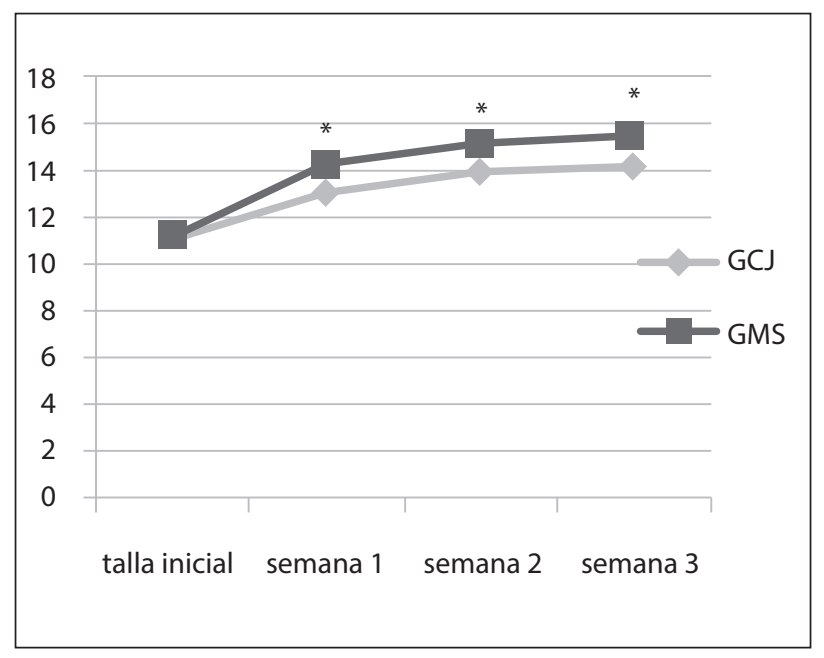

${ }^{*}$ Indica diferencias significativas

Figura 3. Registro de ganacia en talla en hámster dorado control y suplementados con probióticos Fuente: elaboración propia

Con respecto a la excreción fecal de nitrógeno, que se interpreta como la digestibilidad de la proteína suministrada en la ración, la figura 4 detalla el comportamiento de esta variable en los dos grupos estudiados. Se observa cómo la excreción fecal de nitrógeno en el grupo suplementado con probióticos fue menor a partir de la primera semana, indicando un mejor aprovechamiento de la proteína dietaría, lo que se correlaciona bien con las mejores tallas y pesos de este mismo grupo poblacional.

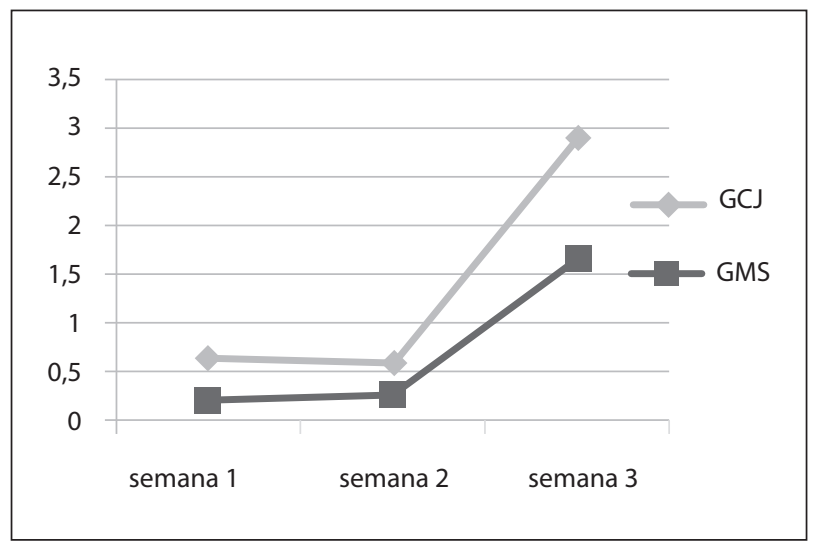

Figura 4. Comportamiento de la excreción de nitrógeno en los dos grupos experimentales en hámster dorado Fuente: elaboración propia 
La excreción fecal de grasa se muestra en la figura 5, que registra el comportamiento de este parámetro. Se observa que, a partir de la primera semana, las diferencias en el contenido de grasa fecal fueron muy evidenetes entre los dos grupos, presentando los animales suplementados con probióticos una mayor excreción, que fue disminuyendo en los otros registros, pero siempre por encima del grupo control, lo que demuestra una menor absorción de este nutriente en los ejemplares suplementados con el probiótico.

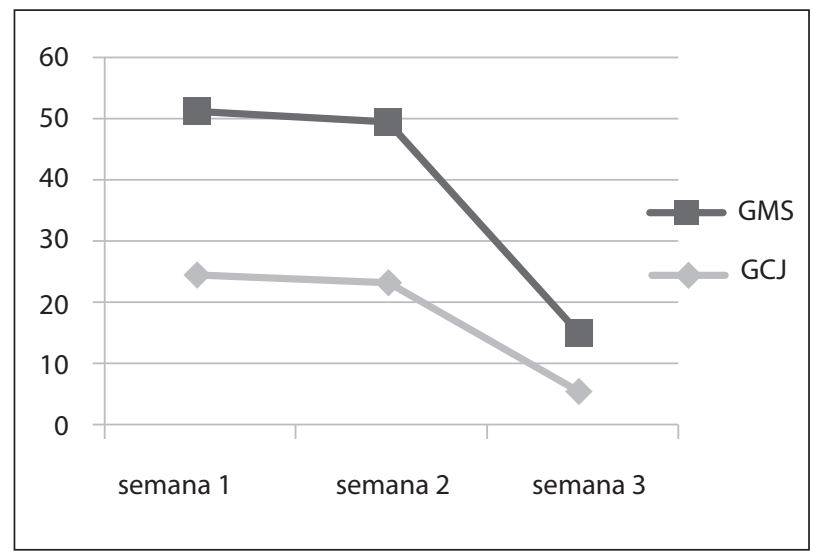

Figura 5. Valores de contenido de grasa fecal en animales con y sin suplemento de probióticos (mgs)

Fuente: elaboración propia

La excreción de cenizas se verifica en la figura 6. Se observa un comportamiento errático, con incremento de la primera a la segunda semana en los dos grupos experimentales $y$, luego, un decremento hacia la tercera semana, siempre con menor tendencia del grupo sometido a suplementación de probióticos.

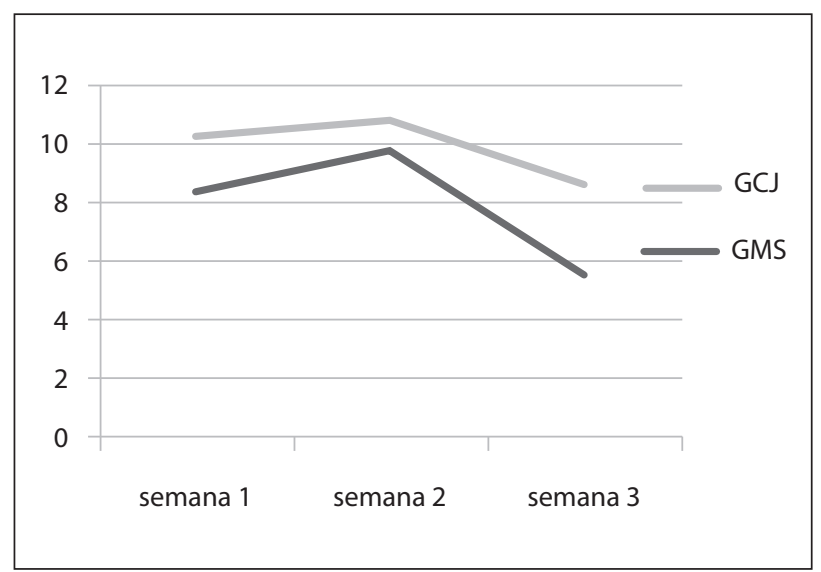

Figura 6. Comportamiento de la ceniza excretada en heces en hámster suplementados y no con probióticos Fuente: elaboración propia
La humedad de las heces también se determinó y este registro se observa en la figura 7 . Se aprecia que el porcentaje de humedad es mayor en las heces de los ejemplares suplementados con probióticos a lo largo del periodo experimental. Este hecho podría determinar una mayor facilidad para la defecación de este grupo, con menor tendencia a problemas de compactación rectal.

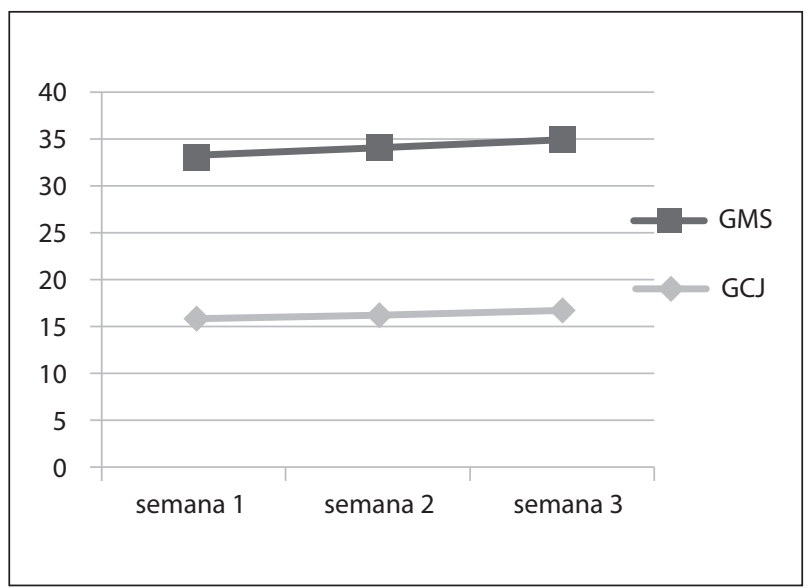

Figura 7. Nivel de humedad en heces de ejemplares suplementados y no con probióticos

\section{Discusión}

El alimento suministrado a los animales experimentales tiene aporte importante de proteína, grasa y ceniza, con alto porcentaje de materia seca; sin embargo, el contenido de grasa es elevado, lo que no correspondería con una dieta adecuadamente balanceada para la especie en estudio.

En la figura 2 se observó la variación en la ganancia de peso, que fue mayor para el grupo experimental, resultado similar al obtenido en lechones en el trabajo de Le Bon et al. [16] y en el realizado en tilapias por Wang et al. [17]. En este último, la ganancia diaria fue de 0,64 $\pm 0,04 \mathrm{~g}$ en el grupo de probióticos, en comparación con el control, que tuvo una ganancia diaria de 0,53 $\pm 0,02 \mathrm{~g}$. Lo anterior puede ser debido a una posible mejor absorción, ya que los probióticos en el tracto digestivo generan cambios microambientales que favorecen la utilización más eficiente de los nutrientes al generar modificaciones de la arquitectura de las vellosidades intestinales [16]. Estudios en peces han demostrado que el uso de probióticos en la ración genera incremento significativo en la actividad enzimática de fermentos pancreáticos, como la tripsina, 
amilasa, lipasa, fosfatasa alcalina y peptidasas [18, 19], situación que debe conducir a una digestión más eficiente del sustrato y pueden influir en una mejor absorción de nutrientes para beneficio del organismo, según la edad (figuras 4 y 5). Se ha documentado que probióticos del género Lactobacillus secretan un amplio rango de exoenzimas, que se suman a las enzimas secretadas por el huésped que no pueden ser diferenciadas [19-21]. A este hecho se suma el resultado de estudios según los cuales a los lechones a los que se les suministraron probióticos en la dieta generaron disminución en el recuento de colonias de bacterias patógenas como la E. Coli, disminución de los cuadros diarreicos posdestete hasta en el $40 \%$ y mejora en la cuantificación de parámetros productivos $[16,22]$.

Durante las tres semanas del experimento, la absorción de proteína es más elevada, puesto que el organismo está en crecimiento y requiere de mayores niveles de este nutriente. En la figura 4 se observa cómo en el grupo experimental se redujo la excreción de nitrógeno fecal, lo cual podría interpretarse como que la absorción de la proteína fue mayor, traducido esto en una tasa de crecimiento y ganancia de peso más elevada (figuras 2 y 3 ).

Siguiendo con la excreción de nitrógeno fecal, se apreció que tuvo un incremento a la tercera semana. Esto se pude atribuir a que a esta edad los animales están alcanzando la etapa adulta y los requerimientos de proteína son más bajos, aspecto que no se manejó con la dieta suministrada, lo cual puede generar una mayor pasantía de proteína sin digerir.

La producción de ácido láctico proveniente de los probióticos genera descenso del pH intestinal, que activa la secreción de secretina [23], que ayuda a estabilizar el pH intestinal y de esta manera ayuda a la acción de enzimas pancreáticas $[18,19]$. De igual manera, al inhibir la secreción gástrica y el vaciamiento gástrico [24], la secretina puede permitir una mayor permanencia de los alimentos en el tubo digestivo y favorecer su digestión, incrementado así la absorción de proteína, como puede deducirse del grupo que recibió el probiótico.

El alto grado de grasa puede también estimular la secreción enzimática pancreática $[8,12,25,26]$, lo cual provoca que, a nivel intestinal, se formen jabones que tienen como efecto estimular la secreción de secretina y colecistocinina, cuya acción aumenta la digestión de proteínas, carbohidratos y grasas, incrementando también los niveles de peptonas, metabolitos de proteínas que tienen efectos directos en la colecistocinina [23].
A esta misma edad, se observó que el contenido de grasa fecal decayó en los dos grupos, lo cual se interpreta como que la absorción de este nutriente aumenta, debido probablemente a que, en estado adulto, la prioridad es energía, siendo la grasa el principal aportante. En este aspecto, el probiótico puede ayudar a controlar niveles de colesterol absorbido para evitar problemas de obesidad.

Los niveles elevados de grasa en las heces del grupo experimental pueden deberse a la acción de los probióticos, que poseen capacidad para desconjugar ácidos biliares, mediante un sistema enzimático que permite la transformación de sales biliares a formas no conjugadas, a las cuales se les atribuye un mayor efecto inhibidor sobre algunos gérmenes [8, 12, 25, 26]. Lo anterior podría traducirse de dos maneras: una, que la acción disminuida de las sales biliares, al ser desconjugadas por los probióticos, tengan un menor efecto emulsificante sobre las grasas dietarias, haciendo que su digestión disminuya y aumente su eliminación vía fecal. La otra posibilidad es que, en el caso de estos roedores, que gozan de un magnífico ciego y poseen una gran digestión fecal bacteriana, la inhibición de bacterias lipolíticas resultante de la interacción con los probióticos generaría una menor digestión de grasa de tipo bacteriano en esta zona y, por tanto, una mayor eliminación de la misma. Se requerirían ensayos específicos para dilucidar esta incógnita.

La excreción abundante de grasa que presentaron los dos grupos puede deberse también a que la dieta presentó niveles altos de este nutriente. Sin embargo, la mayor excreción en el grupo experimental puede atribuirse, adicional a lo mencionado anteriormente, a que la lipasa pancreática es más inestable a cambios de рн о а рн muy cercanos a la acidez.

Cabe resaltar que el probiótico utilizado fue de uso comercial, y por no ser bacterias propias de su hábitat intestinal, la vida media en este ambiente puede ser muy corta, lo que obliga a un suministro diario.

La figura 7 mostró que la humedad fecal de los sujetos experimentales que recibieron el probiótico fue sustancialmente mayor que la de los controles. Esta situación podría explicarse por un mayor peristaltismo intestinal en estos ejemplares, tal y como lo demostraron Landes et al. [27], al utilizar probióticos junto con el mucílago psyllium para remover acumulación de arena en heces en intestino grueso de equinos. También, el efecto sobre el peristaltismo puede ser secundario a la generación de un microambiente intestinal ácido por la producción de ácido láctico [28]. Bach [29] y Chiquette 
[30] mencionan que el uso de probióticos puede estabilizar el pH ruminal por el control del ácido láctico por cuenta de bacterias utilizadoras de lactato, situación que pudo haberse presentado aquí. El ambiente ácido puede llegar a generar irritaciones a nivel epitelial en zonas localizadas, con activación del sistema nervioso entérico, el cual modula los movimientos y secreciones intestinales e incrementa la producción de moco por las células caliciformes, facilitando la formación de masas fecales y estimulando la limpieza del tracto. Este microambiente ácido mejora las funciones protectoras del intestino y el aporte de agua a las heces, brindándole una mejor consistencia y regulándole el peristaltismo.

Con base en los resultados, se puede considerar que el uso adecuado de los probióticos es una estrategia viable en un sistema productivo, que brinda la posibilidad de obtener beneficios y calidad de productos, aumentando de esta manera los niveles de eficiencia y eficacia de las explotaciones pecuarias, convirtiéndose en una alternativa de suplementación de animales de interés zootécnico, al facilitar la absorción de nutrientes, encontrando así una acción de promotor de crecimiento amigable con la salud del consumidor.

Los resultados mostraron que los probióticos utilizados en las condiciones de este estudio y en la muestra poblacional influyeron positivamente en la etapa de crecimiento, ya que estas bacterias poseen proteasas y amilasas que facilitan la digestión y absorción de nutrientes, por lo que se los puede catalogar como promotores de crecimiento, pudiendo así eliminar de los recursos zootécnicos el uso de hormonas causantes de efectos adversos en los consumidores.

Es necesario tener los requerimientos básicos de los probióticos para cada especie, ya que si este es suministrado en altas cantidades puede llegar a: acidificar tanto la luz intestinal, hasta el punto de producir úlceras.

\section{Referencias}

[1] Fuller R. Probiotics in Man and Animal. J Applied Bacter. 1989;66(5):365-78.

[2] Pino A. Efecto de los probióticos en la fisiología animal [Ensayo]. La Habana, Cuba: Instituto de Ciencia Animal y Universidad Agraria de la Habana; 2007.

[3] Galina $M$, et al. Cinética ruminal y crecimiento de cabritos suplementados con un probiótico de bacterias ácido lácticas. Pastos y forrajes. 2009;32(4):1-12.

[4] Modesto M, D’Aimmo M, Stefanini I, Trevesi P. Filippi S, et al. A Novel Strategy to Select Bifidobacterium Strains an Prebiotics as Natural Growth Promoters in Newly Weaned Pigs. Livestock Science. 2009;122:248-258.

[5] Vallejo F, Toro M. Análisis microbiológico en yogurt con probióticos. Bol Micol. 2002;17:15-9.

[6] Lázaro C, Carcelén F, Torres M, Ara M. Efecto de probióticos en el alimento de marranas sobre los parámetros productivos de lechones. Rev Inv Vet Peru. 2005;16(2):97-102.

[7] Schrezenmeir J, Vrese M. Probiotics, Prebiotics and Synbiotics: Approaching a Definition. Am J Clin Nutr. 2001;73(2):361S-364S.

[8] Puertollano E, Puertollano M, Álvarez G, Pablo M. Probióticos: aspectos críticos de su eficacia sobre la salud. Actualidad Sem. 2008;45:28-33.

[9] Miranda N. Probióticos y micronutrientes: ¿son útiles para el tratamiento de la diarrea aguda? Bol Med Hosp Infat Mex. 2008;65(3):157-66.

[10] De Vuyst L, Falony G, Leroy F. Probiotics in Fermented Sausages. Meat Science. 2008;80(1):75-78.

[11] Escalante LA. El potencial de la manipulación de la flora intestinal por medios dietéticos sobre la salud humana. Enf Inf y Micro. 2001;21(3):106-14.

[12] Martínez C, Mesa del Castillo M. Probióticos: ¿fantasía o realidad? An Med Interna. 2005;22(2):53-4.

[13] Iñiguez C, Acedo E. Mecanismos de adhesión al tracto intestinal y antagonismo de Bifidobacterium. RESPYN. 2006;7(2):1-10.

[14] Barron MP, Serrano GC, Villarreal C, Mata BD, Verduzco JA, Morales MR. Acción inhibitoria de probióticos sobre el crecimiento axenico in vitro de Entamoeba histolytica. RESPYN. 2006;7(2):23-29.

[15] Murphy C, Murphy S, O’Brien F, O’Donoghue M, Boileau T, et al. Metabolic Activity of Probiotics - Oxalate Degradation. Vet Microbiol. 2009;136 (1-2):100-107.

[16] Le Bon M, Davies H, Glynn C, Thompson C, Madden M, et al. Influence of Probiotics on Gut Health in the Weaned Pig. Livestock Science. 2010;133(1):179-81.

[17] Wang YB, Tian ZQ, Yao JT, Li WF. Effect of Probiotics, Enteroccus faecium on Tilapia (Oreochromis 
niloticus) Growth Performance and Immune Response. Aquaculture. 2008;277:203-07.

[18] Tovar D, Zambonino I, Cahu C, Gatesoupe F, Vázquez R. Influence of Dietary Live Yeast on European Sea Bass (Dicentrarchus labrax) Larvae Development. Aquaculture. 2004;234(1-4):415-427.

[19] Suzer C, Çoban D, Kamaci H, Saka Ş, Firat K, et al. Lactobacillus spp. Bacteria as Probiotics in Gilthead Sea Bream (Sparus aurata) Larvae: Effects on Growth Performance and Digestive Enzyme Activities. Aquaculture. 2008;280(1-4):140-5.

[20] Moriarty D. Microbial Biotechnology: A Key Ingredient for Sustainable Aquaculture. Inf Fish Int. 1996;4(96):29-33.

[21] Moriarty D. Control of Luminous Vibrio Species in Penaeid Aquaculture Ponds. Aquaculture. 1998;164(1-4):351-58.

[22] Taras D, Vahjen W, Simon O. Probiotics in Pigs Modulation of their Intestinal Distribution and of their Impact on Health and Performance. Livestock Science. 2007;108:229-31.

[23] Engelhardt WV, Breves G. Fisiología veterinaria. Zaragoza, España: Acribia; 2005.

[24] Hall JE. Guyton and Hall Textbook of Medical Physiology. 10. ${ }^{\mathrm{a}}$ ed. Filadelfia: Saunders Elsevier; 2000.
[25] Oropeza M, Posadas E, Cervantes J. Prevención de afecciones gastrointestinales mediante el uso de probióticos en becerros Holstein lactantes. Vet Mex. 1998;29:197-201.

[26] García F, González B. Criterios de calidad de los microorganismos probióticos y evidencias sobre efectos hipocolesterolémicos. RESPYN. 2006;7:12-7.

[27] Landes A, Hassel D, Funk D, Hill A. Fecal Sand Clearance Is Enhanced with a Product Combining Probiotics, Prebiotics, and Psyllium in: Clinically Normal Horses. J Equine Vet Sci. 2008;28(2):79-84.

[28] Medina B, Girard ID, Jacotot E, Julliand V. Effect of a Preparation of Saccharomyces cerevisiae on Microbial Profiles and Fermentation Patterns in the Large Intestine of Horses Fed a High Fiber or a High Starch Diet. J Anim Sci. 2002;80:2600-9.

[29] Bach A. The Importance of Ruminal pH and the Impact of Probiotics on Reducing the Incidence of Subacute Acidosis. En: Proceedings of the 43rd Eastern Nutrition Conference. Quebec: Animal Nutrition Association of Canada; 2007. p. 7-20.

[30] Chiquette J. Evaluation of the Protective Effect of Probiotics Fed to Dairy Cows during a Subacute Ruminal Acidosis Challenge. Animal Feed Science and Technology. 2009;153:278-91. 